\title{
KH-type splicing regulatory protein is involved in esophageal squamous cell carcinoma progression
}

\author{
Yuji Fujita ${ }^{1,2, *}$, Kiyoshi Masuda ${ }^{1, *}$, Junichi Hamada ${ }^{1,2, *}$, Katsutoshi Shoda1,2, Takuya \\ Naruto1, Satoshi Hamada1 ${ }^{1}$ Yuko Miyakami ${ }^{1}$, Tomohiro Kohmotoㄹ, Miki Watanabe ${ }^{1}$, \\ Rizu Takahashi ${ }^{1}$, Shoichiro Tange ${ }^{1}$, Masako Saito ${ }^{1}$, Yasusei Kudo ${ }^{3}$, Hitoshi \\ Fujiwara², Daisuke Ichikawa ${ }^{2,4}$, Akira Tangoku' ${ }^{5}$ Eigo Otsuji ${ }^{2}$ and Issei Imoto ${ }^{1}$ \\ ${ }^{1}$ Department of Human Genetics, Graduate School of Biomedical Sciences, Tokushima University, Tokushima, Japan \\ ${ }^{2}$ Division of Digestive Surgery, Department of Surgery, Kyoto Prefectural University of Medicine, Kyoto, Japan \\ ${ }^{3}$ Department of Oral Molecular Pathology, Graduate School of Biomedical Sciences, Tokushima University, Tokushima, Japan \\ ${ }^{4}$ First Department of Surgery, Faculty of Medicine, University of Yamanashi, Yamanashi, Japan \\ ${ }^{5}$ Department of Thoracic, Endocrine Surgery and Oncology, Institute of Biomedical Sciences, Tokushima University Graduate \\ School, Tokushima, Japan \\ "These authors contributed equally to this work \\ Correspondence to: Issei Imoto, email: issehgen@tokushima-u.ac.jp
}

Keywords: KHSRP, oncogene, RNA-binding protein, microRNA, esophageal squamous cell carcinoma

Received: June 22, $2017 \quad$ Accepted: August 25, $2017 \quad$ Published: September 15, 2017

Copyright: Fujita et al. This is an open-access article distributed under the terms of the Creative Commons Attribution License 3.0 (CC BY 3.0), which permits unrestricted use, distribution, and reproduction in any medium, provided the original author and source are credited.

\section{ABSTRACT}

KH-type splicing regulatory protein (KHSRP) is a multifunctional RNA-binding protein, which is involved in several post-transcriptional aspects of RNA metabolism, including microRNA (miRNA) biogenesis. It affects distinct cell functions in different tissues and can have an impact on various pathological conditions. In the present study, we investigated the oncogenic functions of KHSRP and their underlying mechanisms in the pathogenesis of esophageal squamous cell carcinoma (ESCC). KHSRP expression levels were elevated in ESCC tumors when compared with those in non-tumorous tissues by immunohistochemistry, and cytoplasmic KHSRP overexpression was found to be an independent prognosticator for worse overall survival in a cohort of 104 patients with ESCC. KHSRP knockdown inhibited growth, migration, and invasion of ESCC cells. KHSRP knockdown also inhibited the maturation of cancer-associated miRNAs, such as miR-21, miR-130b, and miR-301, and induced the expression of their target mRNAs, such as BMP6, PDCD4, and TIMP3, resulting in the inhibition of epithelial-to-mesenchymal transition. Our findings uncover a novel oncogenic function of KHSRP in esophageal tumorigenesis and implicate its use as a marker for prognostic evaluation and as a putative therapeutic target in ESCC.

\section{INTRODUCTION}

Esophageal cancer (EC) occurs worldwide with a variable geographic distribution. In Asian countries such as Japan, esophageal squamous cell carcinoma (ESCC) is a major histological type of $\mathrm{EC}$ and is one of the most aggressive and lethal malignancies $[1,2]$. Despite recent clinical advances in EC treatment, the overall patient prognosis remains poor. Therefore, there remains a great deal that needs to be defined, including effective screening, diagnosis, and management strategies to guide the individualized treatment of ESCC.

$\mathrm{KH}$-type splicing regulatory protein (KHSRP) is a multifunctional single-stranded nucleic acid-binding protein located in both the nucleus and the cytoplasm. KHSRP exerts its numerous cellular functions through the modulation of RNA life and gene expression at various levels, such as microRNA (miRNA) maturation, alternative pre-mRNA splicing, and mRNA localization [3]. During miRNA maturation, KHSRP regulates the 
biogenesis of a subset of miRNAs as a component of both Drosha and Dicer complexes in the nuclear and cytoplasmic compartments, respectively $[4,5]$. Various miRNAs have been reported to contribute to multiple tumorigenic processes, including cell proliferation, invasion, and metastasis, through changing the expression of oncogenes and tumor suppressor genes [6]. However, the function of KHSRP seems to vary in different cancers [7-11], and the roles and mechanisms of KHSRP in the tumorigenesis of ESCC remain completely unknown.

In this study, we report that KHSRP exerts oncogenic activity in ESCC cells, at least partly, by inducing the expression of a set of oncogenic miRNAs, including miR-21, miR-130b, and miR-301a, and by suppressing the downstream inhibitors of epithelial-tomesenchymal transition (EMT), such as BMP6, PDCD4, and TIMP3, resulting in the malignant progression of this disease.

\section{RESULTS}

\section{KHSRP expression and its association with clinicopathological characteristics of ESCC}

To determine whether KHSRP is involved in esophageal carcinogenesis, immunohistochemical (IHC) staining with an antibody that specifically recognizes KHSRP was performed in surgically resected esophageal tissues (Figure 1A). KHSRP immunoreactivity was not observed in the cytoplasm and the nucleus of nontumorous epithelia. In carcinoma in situ, KHSRP staining was observed, predominantly in the nucleus, whereas it was observed in both the cytoplasm and the nucleus in advanced ESCC tumors. A similar pattern of KHSRP immunoreactivity was observed in squamous cell carcinomas of other tissues (Supplementary Figure 1A).

We then examined the clinicopathological significance of KHSRP expression in primary ESCC tumors based on the IHC staining patterns. Among the 104 ESCC cases without preoperative chemotherapy, positive cytoplasmic and nuclear KHSRP immunoreactivities were observed in $59(56.7 \%)$ and 68 (65.4\%) cases, respectively, based on their intensity scores (Table 1). No significant association was observed between any of the clinicopathological factors and cytoplasmic or nuclear KHSRP immunoreactivity, except for histological grading. However, venous invasion (v) and the depth of tumor invasion (pT) tended to be associated with cytoplasmic and nuclear KHSRP immunoreactivities. Notably, KaplanMeier survival estimates showed that positive cytoplasmic KHSRP immunoreactivity was significantly associated with worse overall survival $(P=0.003)$, whereas nuclear KHSRP immunoreactivity was not (Figure 1B). Similarly, positive cytoplasmic KHSRP immunoreactivity tended to be associated with worse recurrence-free survival probability $(P=0.053)$, whereas nuclear KHSRP immunoreactivity was not (Supplementary Figure 1B). In the Cox proportional hazards regression model, cytoplasmic KHSRP immunoreactivity and pT and $\mathrm{N}$ stage $(\mathrm{pN})$ categories were statistically significant prognosticators for overall survival by univariate analyses (Table 2). Multivariate analyses showed that cytoplasmic KHSRP immunoreactivity and $\mathrm{pT}$ and $\mathrm{pN}$ categories were independent predictive factors regardless of the models used, suggesting that overexpressed KHSRP was involved in the development and/or progression of ESCC through cytoplasmic localization. Therefore, we examined the expression level and function of KHSRP in a panel of ESCC cell lines.

\section{Involvement of KHSRP in ESCC cell function}

KHSRP mRNA overexpression was detected in 27 out of the 45 ESCC cell lines when compared with normal esophagus (control) by quantitative real-time PCR (qPCR, Supplementary Figure 2A). In contrast, KHSRP protein overexpression was detected in most ESCC cell lines compared with normal esophageal mucosa, although the pattern of KHSRP protein expression levels was similar to that of KHSRP mRNA and discrepancies between mRNA and protein levels were observed in some cell lines to some extent (Supplementary Figure 2B).

To gain insight into the potential functions of KHSRP, the overexpression of which could contribute to esophageal carcinogenesis, we first tested the effects of KHSRP-specific small interfering RNAs (siRNAs) on cell proliferation using cell lines with relatively high KHSRP expression. By silencing endogenous KHSRP using three different siRNAs (Figure 2A and 2B), cell proliferation was slightly, but significantly, suppressed in ESCC cells (Figure 2C). Knockdown of endogenous KHSRP also inhibited spheroid formation in anchorage-independent in vitro 3D cell culture (Figure 2D). Protein levels of cell cycle inhibitors (p21 ${ }^{\text {WAF1/Cip1 }}$ and p2 $7^{\text {Kip } 1}$ ) were increased by knocking down endogenous KHSRP (Figure 2E), although discrepancies between their mRNA and protein levels were observed (Supplementary Figure 3A).

We then assessed the effect of KHSRP knockdown on cell mobility and invasion using scratch-wound healing and Transwell assays. Scratch-wound healing assays revealed that wound closure occurred at a slower rate in KHSRP-knockdown ESCC cells when compared with control cells (Figure 2F and Supplementary Figure 3B). In Transwell assays, uncoated and Matrigel-coated membranes were used to examine cell migration and invasion, respectively. Transwell assays showed that the number of KHSRP siRNA-transfected cells that migrated into or invaded the lower chamber was significantly lower than that of control cells (Figure 2G, Supplementary Figure $3 \mathrm{C}$ and $3 \mathrm{D})$. Elevated and reduced expression of the epithelial marker (CDH1) and EMT inducer (ZEB1) proteins, respectively, were observed in KHSRP- 
Table 1: Association between clinicopathological characteristics and KHSRP expression

\begin{tabular}{|c|c|c|c|c|c|c|c|c|c|c|c|}
\hline \multirow{2}{*}{ Clinicopathological factors } & \multirow{3}{*}{$\begin{array}{c}n \\
104\end{array}$} & \multicolumn{4}{|c|}{ KHSRP immunoreactivity (Cytoplasm) } & \multirow{3}{*}{$P$ value $^{a}$} & \multicolumn{4}{|c|}{ KHSRP immunoreactivity (Nucleus) } & \multirow{3}{*}{$P$ value $^{\mathrm{a}}$} \\
\hline & & \multicolumn{2}{|c|}{ High (\%) } & \multicolumn{2}{|c|}{ Low $(\%)$} & & \multicolumn{2}{|c|}{ High (\%) } & \multicolumn{2}{|c|}{ Low (\%) } & \\
\hline Total & & 59 & $(56.7)$ & 45 & $(43.3)$ & & 68 & $(65.4)$ & 36 & $(34.6)$ & \\
\hline \multicolumn{12}{|l|}{ Gender } \\
\hline Male & 85 & 46 & $(54.1)$ & 39 & $(45.9)$ & 0.3116 & 54 & $(63.5)$ & 31 & $(36.5)$ & 0.5944 \\
\hline Female & 19 & 13 & $(68.4)$ & 6 & $(31.6)$ & & 14 & (73.7) & 5 & $(26.3)$ & \\
\hline \multicolumn{12}{|l|}{ Age } \\
\hline Mean $\pm \mathrm{SD}(\mathrm{yr})$ & $64.1 \pm 8.4$ & 63.2 & \pm 7.6 & 65.3 & \pm 9.3 & 0.2031 & 64.1 & \pm 8.1 & 64.1 & \pm 9.1 & 0.9758 \\
\hline \multicolumn{12}{|l|}{ Histopathological grading } \\
\hline $\begin{array}{l}\text { Well and moderately } \\
\text { differentiated }\end{array}$ & 75 & 43 & $(57.3)$ & 32 & $(42.7)$ & 1.0000 & 44 & $(58.7)$ & 31 & $(41.3)$ & 0.0227 \\
\hline Poorly differentiated & 29 & 16 & $(55.2)$ & 13 & $(44.8)$ & & 24 & $(82.8)$ & 5 & $(17.2)$ & \\
\hline \multicolumn{12}{|l|}{ Lymphatic invasion (ly) } \\
\hline Negative & 45 & 23 & $(51.1)$ & 22 & $(48.9)$ & 0.3263 & 31 & $(68.9)$ & 14 & $(31.1)$ & 0.5397 \\
\hline Positive & 59 & 36 & $(61.0)$ & 23 & $(39.0)$ & & 37 & $(62.7)$ & 22 & $(37.3)$ & \\
\hline \multicolumn{12}{|l|}{ Venous invasion (v) } \\
\hline Negative & 73 & 37 & $(50.7)$ & 36 & $(49.3)$ & 0.0828 & 44 & $(60.3)$ & 29 & $(39.7)$ & 0.1166 \\
\hline Positive & 31 & 22 & $(71.0)$ & 9 & $(29.0)$ & & 24 & $(77.4)$ & 7 & $(22.6)$ & \\
\hline \multicolumn{12}{|l|}{ Depth of tumor invasion (pT) } \\
\hline pT1 & 56 & 27 & $(48.2)$ & 29 & $(51.8)$ & 0.0747 & 32 & $(57.1)$ & 24 & $(42.9)$ & 0.0654 \\
\hline pT2-4 & 48 & 32 & $(66.7)$ & 16 & $(33.3)$ & & 36 & $(75.0)$ & 12 & $(25.0)$ & \\
\hline \multicolumn{12}{|l|}{$\mathrm{N}$ stage $(\mathrm{pN})$} \\
\hline $\mathrm{pNO}$ & 55 & 32 & $(58.2)$ & 23 & $(41.8)$ & 0.8435 & 35 & $(63.6)$ & 20 & $(36.4)$ & 0.8367 \\
\hline pN1-3 & 49 & 27 & $(55.1)$ & 22 & $(44.9)$ & & 33 & (67.3) & 16 & $(32.7)$ & \\
\hline \multicolumn{12}{|l|}{ pStage } \\
\hline $\mathrm{pI}$ & 43 & 23 & $(53.5)$ & 20 & $(46.5)$ & 0.6882 & 24 & $(55.8)$ & 19 & $(44.2)$ & 0.0976 \\
\hline pII-VI & 61 & 36 & $(59.0)$ & 25 & $(41.0)$ & & 44 & $(72.1)$ & 17 & (27.9) & \\
\hline
\end{tabular}

Statistically significant values are in boldface type.

${ }^{\text {a }} P$ values are from $\chi 2$ or Fisher's exact test and were statistically significant at $<0.05$.

knockdown cells when compared with control cells by both Western blot analysis (Figure $2 \mathrm{H}$ ) and fluorescent immunocytochemical staining (Supplementary Figure 3E).

To determine the chronic effects of exogenously overexpressed KHSRP on ESCC cell function in vitro, we established stable transfectants that expressed HAtagged KHSRP protein using KYSE1190 and KYSE1250 cells with relatively low expression of endogenous KHSRP (Figure 3A and 3B). Western blot analysis using subcellular components obtained by cell fractionation showed that exogenously expressed KHSRP was detected in both nuclear and cytoplasmic lysates, although most KHSRP was located in the nucleus (Figure 3C). Stable expression of KHSRP slightly, but significantly, increased cell proliferation compared with control cells (Figure 3D). Scratch-wound healing assays indicated an induction of faster wound closure in KHSRP-expressing cells compared with control cells (Figure 3E). Transwell assays showed that the number of cells that migrated into or invaded the lower chamber was significantly higher for KHSRP-expressing cells than for control cells under both conditions (Figure 3F). Higher ZEB1 expression and lower $\mathrm{p} 21^{\mathrm{WAF} 1 / \mathrm{Cip} 1}$, p2 $7^{\mathrm{Kip} 1}$ and/or CDH1 expression were observed in cells exogenously expressing KHSRP, when compared with cells lacking exogenous KHSRP expression (Figure 3G).

\section{Identification of putative target miRNAs for KHSRP}

Because KHSRP seemed to exert a greater effect on migration/invasion than on the proliferation of the ESCC cells, we further investigated the molecular mechanisms of KHSRP-promoted ESCC cell migration/invasion. KHSRP has been shown to promote maturation of miRNAs by binding their conserved sequences in the terminal loop [12] and then to alter TGF $\beta$-induced EMT [10]. Therefore, we screened differentially expressed genes (mRNA) and 
miRNAs in KHSRP-knockdown KYSE850 cells using a microarray analysis. In these cells, 560 and 750 genes were up- and down-regulated, respectively, by $>1.5$-fold compared with control cells (Supplementary Tables 1 and 2). KHSRP knockdown also lowered the expression of 26 miRNAs by $>0.5$-fold compared with control cells (Table 3). Among these miRNAs, the KHSRP knockdowninduced down-regulation was successfully validated with five cancer-associated miRNAs in three ESCC cell lines (Figure 4A).

Three (miR-21, miR-130b, and miR-301a) of these were chosen for further analysis according to their known functions in EMT [13-15]. In 22 KHSRP-overexpressing ESCC cell lines, higher expression levels of miR-21, miR-130b, and miR-301a were detected in 6,11, and 22 lines, respectively, when compared with the normal esophagus (Supplementary Figure 4A-4C). In KHSRPknockdown cells, on the other hand, the expression levels of their primary miRNA precursors (pri-miRNAs) and precursor miRNAs (pre-miRNAs) were significantly increased compared with control cells (Figure 4B and 4C).
Ribonucleoprotein immunoprecipitation (RIP), which was conducted using nuclear or cytoplasmic lysates prepared from HEK293 cells transiently expressing Halotagged KHSRP, followed by qPCR demonstrated the bindings of nuclear and cytoplasmic KHSRP to these primiRNAs (Supplementary Figure 5A) and pre-miRNAs (Supplementary Figure 5B), respectively. Taken together, these results suggested that KHSRP is mainly involved in multiple maturation steps of these three miRNAs to increase their expression levels in ESCC.

Among 560 up-regulated genes in KHSRPknockdown cells, a total of 77 mRNAs were predicted as target genes for at least one of these three miRNAs using DIANA-TarBase v7.0 database (http://diana.imis.athenainnovation.gr/DianaTools/index.php? $\mathrm{r}=$ tarbase/index): 40, 39 and 43 mRNAs for miR-21, miR-130b and miR-301a, respectively (Supplementary Table 3). Pathway analysis of these 77 mRNAs using the Kyoto Encyclopedia of Genes and Genomes (KEGG) database ranked "TGF $\beta$ signaling pathway" and "endocytosis" as functional pathways with nominal $P$-values $<0.05$. However, only "TGF $\beta$

A

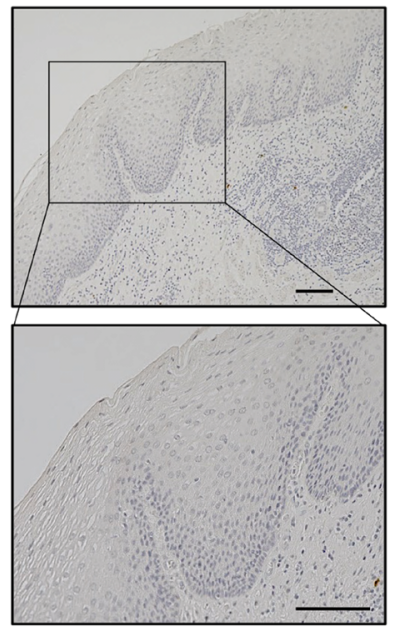

normal

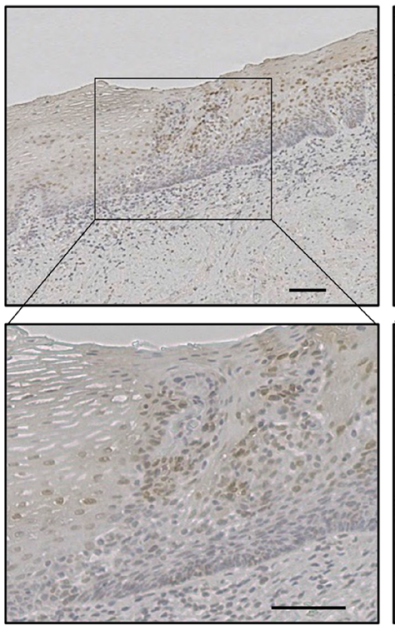

carcinoma in situ

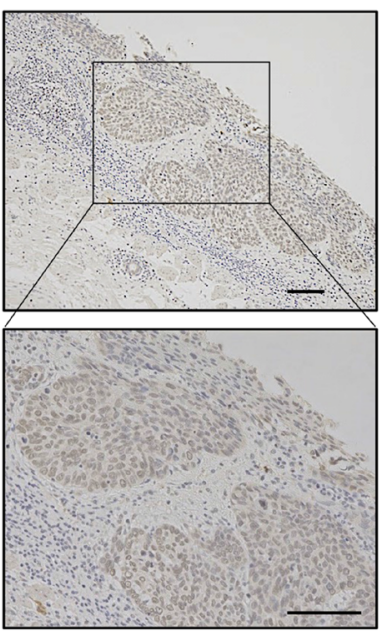

advanced cancer
B

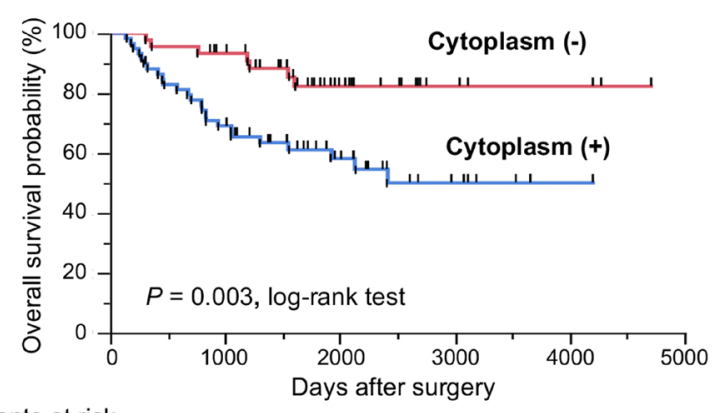

Patients at risk

Cytoplasm (-) 45

Cytoplasm (+) 59

$\begin{array}{llll}39 & 17 & 5 & 3 \\ 40 & 19 & 7 & 1\end{array}$

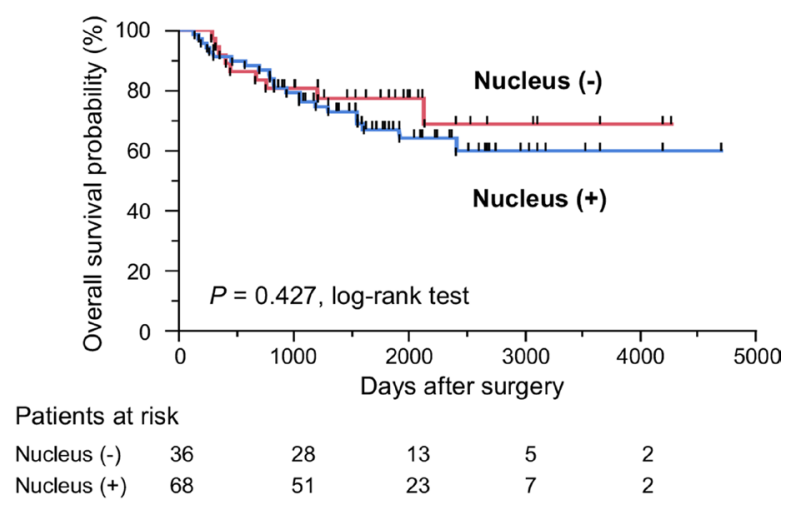

Figure 1: KHSRP protein expression/localization and its association with overall survival in primary ESCC tumors. (A) Representative images of immunohistochemically detected KHSRP protein in normal mucosa, carcinoma in situ, and advanced squamous cell carcinoma of the esophagus. Scale bars, $100 \mu \mathrm{m}$. (B) Kaplan-Meier curves for the overall survival rates of 104 ESCC patients according to the cytoplasmic (left) and nuclear (right) immunoreactivities of KHSRP. 
Table 2: Cox proportional hazard regression analysis for overall survival

\begin{tabular}{|c|c|c|c|c|c|c|c|}
\hline \multirow{3}{*}{ Factor } & \multicolumn{5}{|c|}{ Univariate } & \multicolumn{2}{|c|}{ Multivariate $^{a}$} \\
\hline & \multirow[b]{2}{*}{$\begin{array}{l}\text { Hazard } \\
\text { ratio }\end{array}$} & & & & \multirow[b]{2}{*}{$P$ value } & \multirow{2}{*}{$\frac{\text { Model } 1}{P \text { value }}$} & \multirow{2}{*}{$\frac{\text { Model } 2}{P \text { value }}$} \\
\hline & & \multicolumn{3}{|c|}{$\begin{array}{l}\text { 95\% confidence } \\
\text { interval }\end{array}$} & & & \\
\hline Male versus Female & 1.32 & 0.5552 & - & 3.9080 & 0.5518 & 0.5802 & - \\
\hline \multicolumn{8}{|l|}{ Age (years) } \\
\hline$\geq 65$ versus $<65$ & 1.06 & 0.5285 & - & 2.1734 & 0.8684 & 0.2886 & - \\
\hline \multicolumn{8}{|l|}{ Histopathological grading } \\
\hline Poorly versus Well-moderately differentiated & 1.27 & 0.5708 & - & 2.8320 & 0.5568 & 0.5712 & - \\
\hline \multicolumn{8}{|l|}{ Lymphatic invasion } \\
\hline Positive versus Negative & 2.03 & 0.9880 & - & 4.4942 & 0.0541 & 0.6143 & - \\
\hline \multicolumn{8}{|l|}{ Venous invasion } \\
\hline Positive versus Negative & 1.61 & 0.7646 & - & 3.2637 & 0.2018 & 0.8563 & - \\
\hline \multicolumn{8}{|l|}{ Depth of tumor invasion (pT) } \\
\hline pT2-4 versus pT1 & 3.27 & 1.5888 & - & 7.2324 & 0.0011 & 0.0332 & 0.0229 \\
\hline \multicolumn{8}{|l|}{$\mathrm{N}$ stage $(\mathrm{pN})$} \\
\hline $\mathrm{pN} 1-3$ versus $\mathrm{pN} 0$ & 3.06 & 1.4887 & - & 6.7720 & 0.0021 & 0.0069 & 0.0086 \\
\hline \multicolumn{8}{|l|}{ KHSRP immunoreactivity in the cytoplasm } \\
\hline Positive versus Negative & 3.28 & 1.4964 & - & 8.2336 & 0.0023 & 0.0045 & 0.0059 \\
\hline \multicolumn{8}{|l|}{ KHSRP immunoreactivity in the nucleus } \\
\hline Positive versus Negative & 1.37 & 0.6547 & - & 3.1225 & 0.4153 & - & - \\
\hline
\end{tabular}

Note: Statistically significant values are in boldface type.

${ }^{a}$ Model 1, all factors excluding KHSRP immunoreactivity in the nucleus model were included;

Model 2, a step-wise procedure was used.

signaling pathway" was ranked as a functional pathway with adjusted $P$-value $<0.25$ (Table 4). Of the transcripts annotated as "TGF $\beta$ signaling pathway" and reported as regulators of EMT, we focused on 12 genes $(B M P 6, B T G 2$, CD2AP, EPHA4, EZH1, LTBP1, MXD1, NEO1, PDCD4, $R F F L, S D C 4$ and TIMP3) for further analysis according to their known functions in cancers [13, 16-26]. Increased expression levels of these genes in KHSRP-knockdown cells were successfully validated by qPCR (Figure 4D and Supplementary Figure 5C). The effects of the KHSRP silencing on protein expression levels were assessed with BMP6, PDCD4, and TIMP3 genes according to their known functions in EMT. Compared with control siRNAtreated cells, KHSRP siRNA-treated cells exhibited higher levels of BMP6, PDCD4, and TIMP3 proteins (Figure 4E and Supplementary Figure 5D). Conversely, cells that stably overexpressed HA-tagged KHSRP showed higher levels of miR-21, miR-130b, and miR-301a (Figure 4F) and lower levels of BMP6, PDCD4, and TIMP3 mRNAs and proteins compared with control cells (Figure 4G and Supplementary Figure 5E). We validated correlations among expression levels of KHSRP, these three miRNAs, and their target mRNAs in surgically resected ESCC tumors, whose high-quality RNA was available for qPCR. In two ESCC tumors with positive cytoplasmic KHSRP immunoreactivity, miR-21, miR-130b, and miR-301a expression levels in tumors were higher and $B M P 6$, $P D C D 4$, and TIMP3 mRNA expression levels were lower compared with those in paired non-tumorous tissues, whereas these alterations were not consistently observed in two ESCC tumors with negative cytoplasmic KHSRP immunoreactivity (Supplementary Figure 6A, 6B).

\section{Functional association between KHSRP-targeted miRNAs and their putative target mRNAs}

The proteins encoded by $B M P 6, P D C D 4$, and TIMP3 are known as inhibitors of EMT [13, 16, 26-29]. Therefore, we next tested whether increased KHSRP expression down-regulates their cognate protein levels in ESCC cells by up-regulating miR-21, miR-130b, and/ or miR-301a. Exogenous introduction of each of the miRNA inhibitors into cells with relatively high KHSRP expression induced higher levels of BMP6, PDCD4 and/or TIMP3 proteins (Figure 5A) and mRNAs (Figure 5B) and inhibited cell migration (Figure 5C and Supplementary 
A

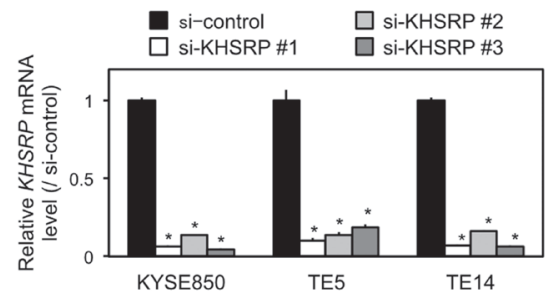

C

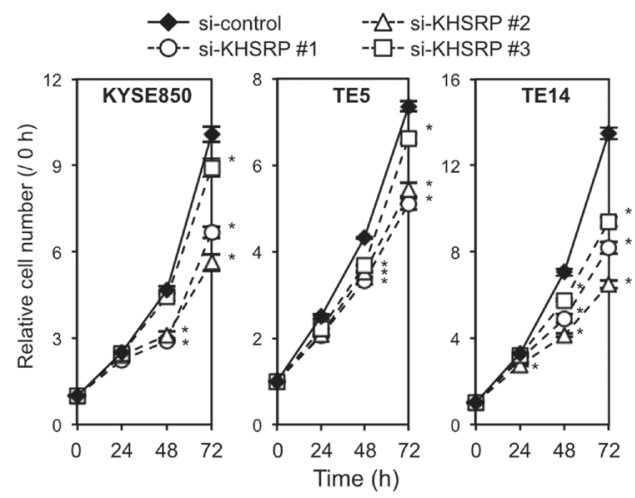

$\mathbf{E}$

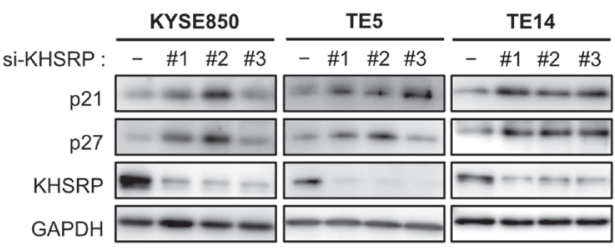

G

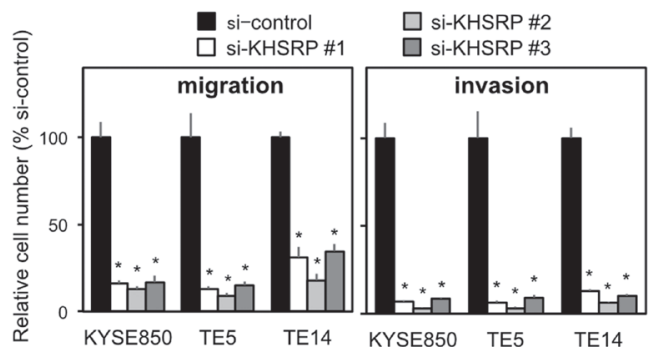

B

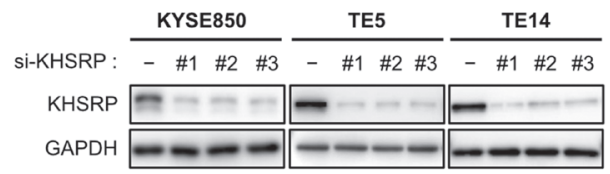

D

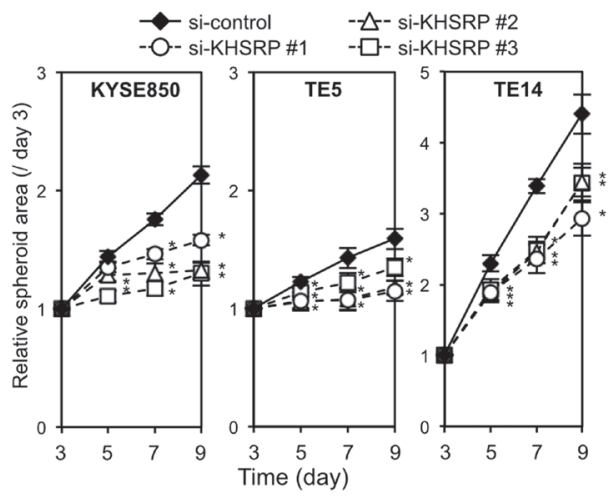

F

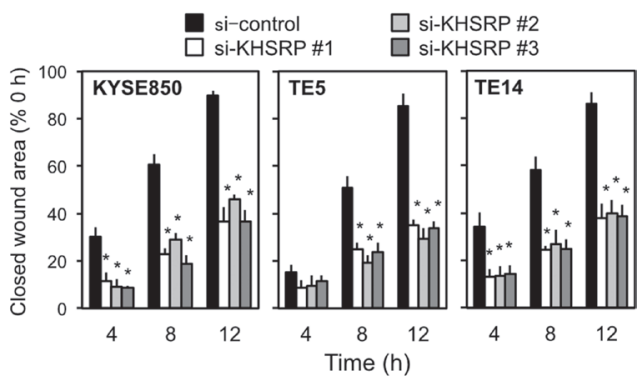

H

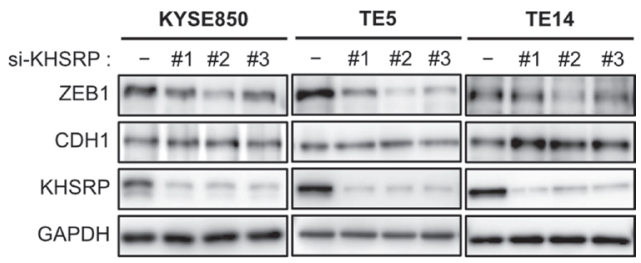

Figure 2: Effects of KHSRP knockdown on cellular function in ESCC cells. (A) ESCC cells with relatively high expression of KHSRP (KYSE850, TE5, and TE14) were transfected with $10 \mathrm{nM}$ of control or KHSRP-specific siRNAs for $48 \mathrm{~h}$ and KHSRP mRNA expression levels were evaluated by qPCR. The values are expressed as fold changes (mean $\pm \mathrm{SD}, n=6$ ) when compared with the respective values in control siRNA-transfected cells. ${ }^{*} P<0.05$. (B) ESCC cells were treated as described in Figure $2 \mathrm{~A}$, and expression levels of KHSRP protein were evaluated by Western blot analysis. (C) ESCC cells were transfected with $10 \mathrm{nM}$ of control or KHSRPspecific siRNAs for $24 \mathrm{~h}$, and cellular proliferation was measured using a WST-8 assay at the indicated times. The values are expressed as fold changes (mean $\pm \mathrm{SD}, n=6$ ) when compared with the respective values in control cells $(0 \mathrm{~h})$. ${ }^{*} P<0.05$. (D) For spheroid formation assay, ESCC cells treated as described in Figure $2 \mathrm{C}$ were seeded in ultra-low attachment 96 -well round bottom plates and incubated for the indicated times (d, days). The areas of spheroids were determined as described in the Materials and Methods section ( $\operatorname{mean} \pm \mathrm{SD}, n=8$ ). ${ }^{*} P<0.05$. (E) ESCC cells were treated as described in Figure 2A, and the levels of $\mathrm{p} 21^{\mathrm{WAF} / \mathrm{Cip} 1}$, $\mathrm{p}^{2} 7^{\mathrm{Kip} 1}$ and KHSRP proteins were determined by Western blot analysis. (F) ESCC cells treated as described in Figure 2C were dispensed into ibidi Culture-Inserts. After $24 \mathrm{~h}$, the Culture-Inserts were removed, and the scratch-wound area was determined as described in the Materials and Methods section (mean $\pm \mathrm{SD}, n=6$ ). The values are expressed as percentages (mean $\pm \mathrm{SD}, n=6$ ) when compared with the respective values in control cells $\left(0\right.$ h). ${ }^{*} P<0.05$. (G) ESCC cells treated as described in Figure $2 \mathrm{C}$ were added onto BD Falcon Cell Culture Inserts coated with (invasion assay) or without (migration assay) Matrigel. After incubation for $48 \mathrm{~h}$, cells on the lower surface of filters were determined as described in the Materials and Methods section (mean $\pm \mathrm{SD}, n=6$ ). ${ }^{*} P<0.05$. (H) ESCC cells were treated as described in Figure 2A, and the expression levels of ZEB1, CDH1, and KHSRP proteins were evaluated by Western blot analysis. 
Table 3: List of the miRNA differentially expressed in KHSRP knockdown cells

\begin{tabular}{|c|c|}
\hline miRNA name & Fold change \\
\hline hsa-miR-130b-3p & 0.015 \\
\hline hsa-miR-15a-5p & 0.017 \\
\hline hsa-miR-10a-5p & 0.019 \\
\hline hsa-miR-324-3p & 0.021 \\
\hline hsa-miR-29c-3p & 0.022 \\
\hline hsa-miR-26a-5p & 0.031 \\
\hline hsa-miR-151b & 0.038 \\
\hline hsa-miR-30a-5p & 0.039 \\
\hline hsa-miR-185-5p & 0.040 \\
\hline hsa-miR-30e-5p & 0.044 \\
\hline hsa-miR-181a-5p & 0.045 \\
\hline hsa-miR-301a-3p & 0.045 \\
\hline hsa-miR-30b-5p & 0.047 \\
\hline hsa-miR-18b-5p & 0.073 \\
\hline hsa-miR-130a-3p & 0.277 \\
\hline hsa-miR-27b-3p & 0.319 \\
\hline hsa-miR-22-3p & 0.327 \\
\hline hsa-miR-331-3p & 0.329 \\
\hline hsa-miR-16-5p & 0.340 \\
\hline hsa-miR-15b-5p & 0.377 \\
\hline hsa-miR-21-5p & 0.388 \\
\hline hsa-miR-31-5p & 0.407 \\
\hline hsa-miR-29a-3p & 0.410 \\
\hline hsa-miR-31-3p & 0.433 \\
\hline hsa-let-7e-5p & 0.449 \\
\hline hsa-let-7b-5p & 0.466 \\
\hline
\end{tabular}

Figure 7A) and invasion (Figure 5D and Supplementary Figure 7B). In contrast, the exogenous introduction of each of the miRNA mimics into KHSRP-knockdown cells restored cell growth (Supplementary Figure 7C) and cell migration (Supplementary Figure 7D), and inhibited the expression levels of BMP6, PDCD4, and TIMP3 proteins (Supplementary Figure 7E), at least in part. These results suggested that overexpressed KHSRP promotes ESCC migration and invasion, at least partly, by the up- regulation of a set of cancer-associated miRNAs and by the suppression of their downstream EMT-inhibiting proteins.

\section{DISCUSSION}

To our knowledge, this is the first report that demonstrates the clinical and functional significance of KHSRP in ESCC tumorigenesis. Overexpression of 
KHSRP in tumor cells, particularly in the cytoplasm, was an independent prognosticator for overall survival. KHSRP mainly promoted cell migration/invasion with minimal induction of ESCC cell proliferation. Many studies in the past 20 years have demonstrated that
KHSRP-dependent regulation of RNA metabolism affects distinct cell functions in different tissues and can have an impact on pathological conditions. However, very few reports have described KHSRP function in the context of human carcinomas. The overall role of KHSRP in
A

B
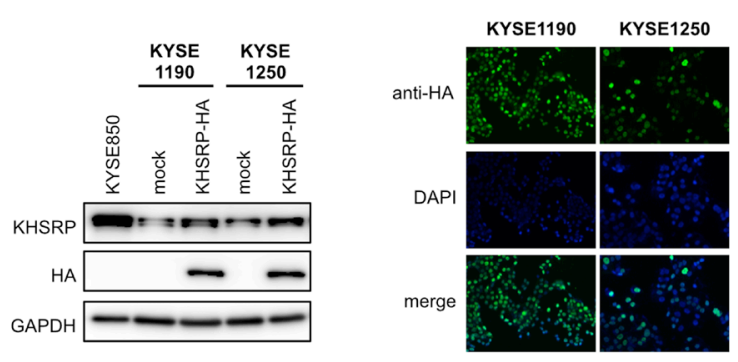

E
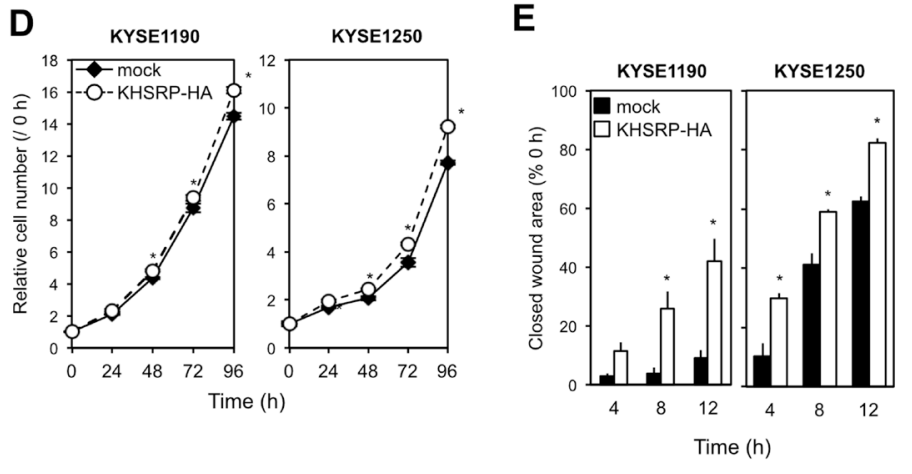

C

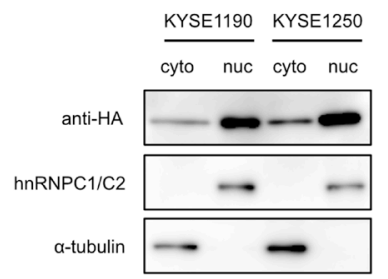

$\mathbf{F}$

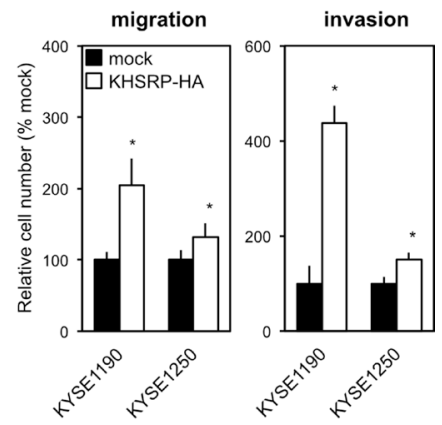

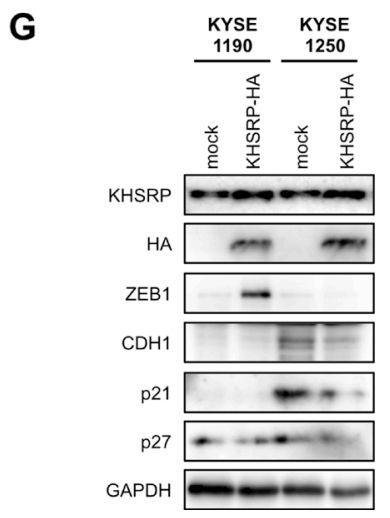

Figure 3: KHSRP overexpression promotes ESCC cell migration and invasion. (A) Levels of endogenous KHSRP and exogenous HA-tagged KHSRP proteins in ESCC cells with relatively low expression of endogenous KHSRP (KYSE1190 and KYSE1250) that stably express HA-tagged exogenous KHSRP were analyzed by Western blot analysis. (B) Representative images of ESCC cells stably expressing HA-tagged exogenous KHSRP detected by FIC with an anti-HA antibody (green). Nuclei were counterstained with DAPI (blue). Scale bars, $20 \mu \mathrm{m}$. (C) Subcellular distribution of exogenously expressed KHSRP. Cytoplasmic and nuclear fractions were prepared from KYSE1190 and KYSE1250 cells stably expressing HA-tagged KHSRP. Exogenously expressed KHSRP, $\alpha$-tubulin (cytoplasmic marker), and hnRNPC1/C2 (nuclear marker) were detected by Western blot analysis. (D) The number of viable cells of each stable transfectant was assessed using a WST assay at the indicated times. The values are expressed as fold changes (mean $\pm \mathrm{SD}, n=6)$ when compared with the respective control values $(0 \mathrm{~h}) .{ }^{*} P<0.05$. (E) Each stable transfectant was dispensed into the ibidi Culture-Inserts. The area of the scratchwound was determined as described in Figure $2 \mathrm{~F}$. The values are expressed as percentages (mean $\pm \mathrm{SD}, n=6$ ) when compared with the respective values in control cells $(0 \mathrm{~h}) .{ }^{*} P<0.05$. (F) Each stable transfectant was transferred into the upper chamber of BD Falcon Cell Culture Inserts coated with (invasion assay) or without (migration assay) Matrigel. After incubation for $48 \mathrm{~h}$, cells on the lower surface of filters were determined as described in Figure $2 \mathrm{G}$ (mean $\pm \mathrm{SD}, n=3$ ). ${ }^{*} P<0.05$. (G) Levels of endogenous KHSRP, exogenous HA-tagged KHSRP, ZEB1, CDH1, p2 $1^{\mathrm{WAF} 1 / \mathrm{Cip} 1}$, and 2 $^{\mathrm{Kip} 1}$ proteins were measured by Western blot analysis. 
Table 4: Functional pathways of 77 target mRNAs of miR-21, miR-130b and miR-301a

\begin{tabular}{lcc}
\hline Term & $\boldsymbol{P}$ value & Adjusted $\boldsymbol{P}$ value (FDR) \\
\hline hsa04350 TGF-beta signaling pathway & 0.003 & 0.117 \\
hsa04144 Endocytosis & 0.025 & 0.388 \\
\hline
\end{tabular}

carcinogenesis has been controversial, because KHSRP exerts oncogenic or tumor suppressive functions through various mechanisms in different cancer types. It has been reported that KHSRP promotes cell motility in human liver cancer [7, 30] and osteosarcoma [31] cells, and promotes cell proliferation, but not migration, in small cell lung cancer cells [11]. In contrast, Yang et al. showed the suppressive effects of KHSRP on migration ability of glioblastoma cells [9]. In addition, two independent studies have demonstrated that high KHSRP expression levels were associated with longer overall survival in glioblastoma multiforme $[9,32]$. Because some RNAbinding proteins can act as both positive and negative post-transcriptional regulators in cell type-specific manner [33-36], the finding that KHSRP could work as an oncogene in ESCC was not surprising. It is evident that the consequences of altered KHSRP levels are different in distinct tumors and may reflect cell-restricted functions of KHSRP that rely on the participation of the protein in distinct multiprotein complexes and on its binding to various targets in different cell lineages [3].

miRNAs, the maturation of which is enhanced by KHSRP, play important roles in controlling various cellular functions. Although numerous studies over the past decade have shown cell type-specific changes in miRNA expression profiles, knowledge of the mechanisms that underlie their deregulation in ESCC is still limited [6, 37]. We observed deregulated maturation of the potential target miRNAs with an increase in their precursors in KHSRPknockdown cells. Some of these have been reported to exert cancer-associated functions [6, 37], indicating that deregulation of KHSRP-miRNA interplay may, at least in part, affect the ESCC-specific miRNA expression profile. It has been demonstrated that KHSRP binds to the conserved G-rich elements in the terminal loop of a cohort of miRNA precursors and promotes their maturation by facilitating their association with Drosha in the nucleus or with Dicer in the cytoplasm [12]. Indeed, the bindings of nuclear and cytoplasmic KHSRP to pri-miRNAs and pre-miRNAs of the three miRNAs, respectively, were detected by our RIPqPCR experiments. However, none of the three miRNAs that we identified as KHSRP targets in ESCC has typical G-rich elements, such as GGG triplets, in the terminal loop of their precursors. Notably, it has been demonstrated that KHSRP is bound to the precursor of miR-21, and its knockdown reduced the expression levels of mature miR21 in HeLa and NIH3T3 cells [12]. Therefore, it remains unclear whether KHSRP increases the expression levels of these three miRNAs through known mechanisms.
The comprehensive elucidation of molecules that execute the EMT program still remains an important question in the field of cancer research, because the identification of key molecules within this network is critical from a therapeutic perspective. We demonstrated that KHSRP induced EMT by the up-regulation of oncogenic miRNAs, such as miR-21, miR-130b, and miR-301a. Overexpression of miR-21 is known to induce EMT by targeting PDCD4 [13, 27, 28] and TIMP3 [26, 29] mRNAs in various cancer types, including ESCC. EMT-suppressor BMP6 is a known target of miR-130b and miR-301a [38]. Therefore, KHSRP coordinates the expression of a gene cluster that encodes proteins within EMT-related and/or TGF $\beta$ signaling pathways. This suggests that KHSRP could be a possible therapeutic target for simultaneous and efficient manipulation of various target genes/pathways contributing to the malignant progression of ESCC. However, in contrast to our findings, several studies have revealed suppressive effects of KHSRP on EMT in murine immortalized mammary epithelial cells $[10,39]$ and laryngeal squamous cell carcinoma cells [40].

In addition to miRNA maturation, KHSRP plays crucial roles in a variety of cellular processes, such as alternative pre-mRNA splicing and mRNA localization. Therefore, it is possible that oncogenic functions of overexpressed KHSRP in ESCC cells are also mediated through regulation of these processes. In KHSRPoverexpressing ESCC cells, inhibition of each of the endogenously expressed target miRNAs released the upregulation of the corresponding targets at both mRNA and protein expression levels, and inhibited cell migration/ invasion (Figures 5A-5D), whereas introduction of each of the miRNA mimics into KHSRP-knockdown cells inhibited expression levels of the corresponding target proteins and restored cell migration, at least partly. However, each of the three miRNAs decreased expression levels of tested genes other than their possible direct targets in ESCC cells (Figure 5A, Supplementary Figure 7E). These results suggested that the effects of overexpressed KHSRP on EMT in ESCC cells could be explained by direct and indirect miRNA-mediated pathways shown in Figure 5E. In addition, it is possible that KHSRP employs various strategies involving other than these three miRNAs and/or their targets to promote EMT of ESCC, because the effects of KHSRP on the expression of EMT-related molecules, including ZEB1, CDH1, BMP6, PDCD4, and TIMP3, were different among the selected ESCC cell models. KHSRP has been reported 
A

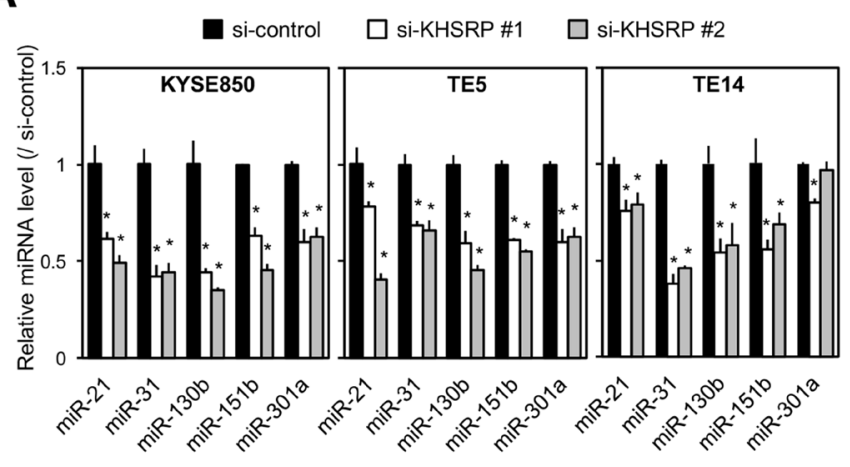

C

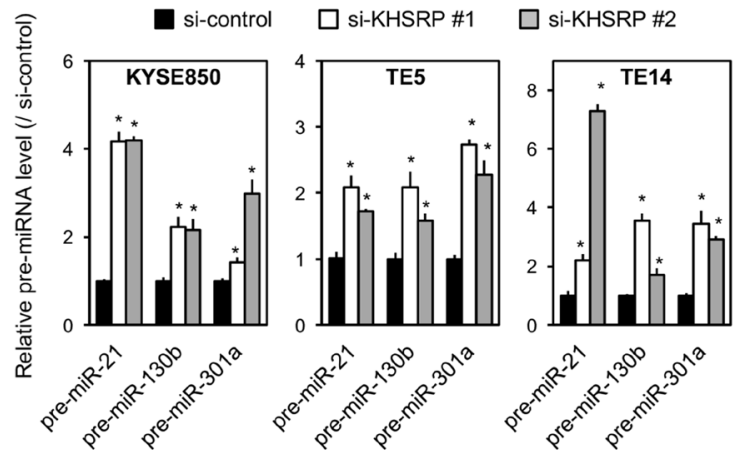

B

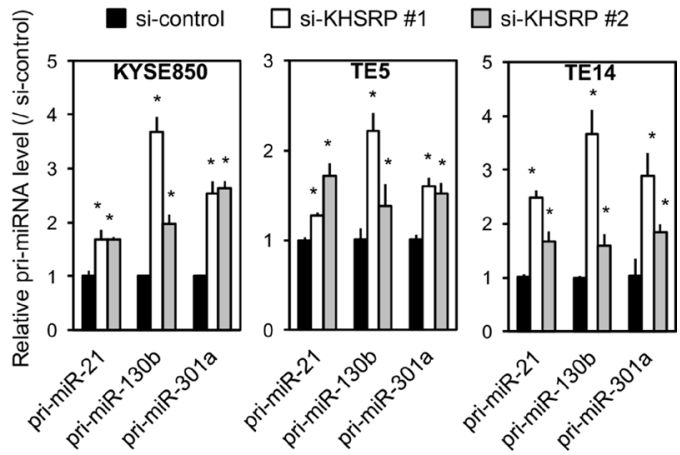

D

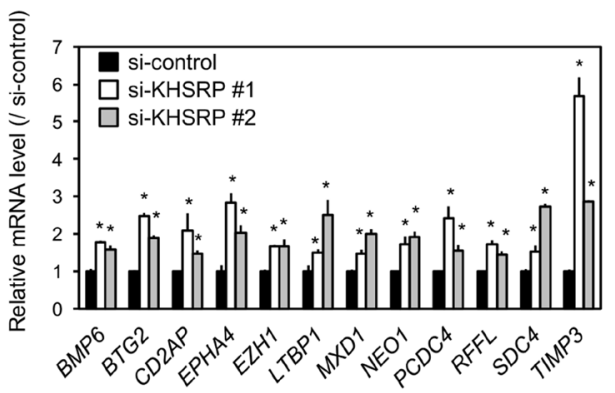

E

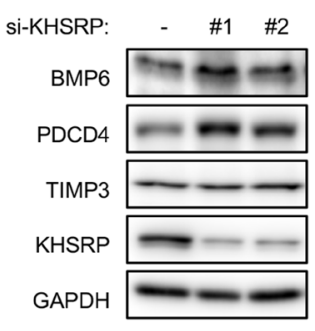

$\mathbf{F}$

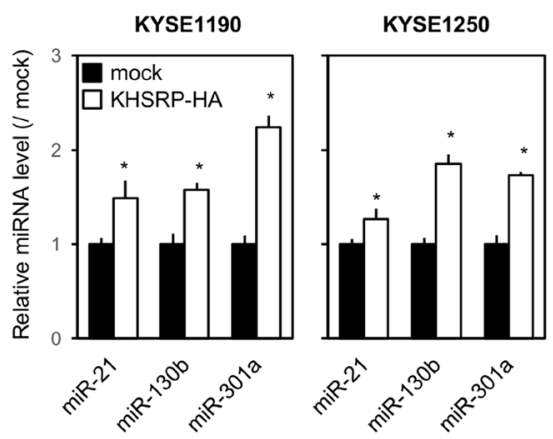

G

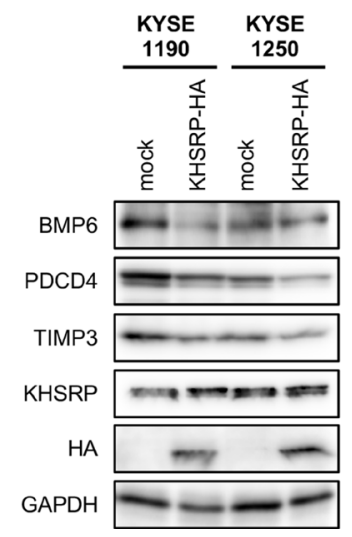

Figure 4: Effects of KHSRP knockdown or overexpression on the expression of putative target miRNAs and protein levels of their target genes in ESCC cells. (A) ESCC cells were transfected with $10 \mathrm{nM}$ of control or KHSRP-specific siRNAs for 48 $\mathrm{h}$, and the amounts of miR-21, miR-31, miR-130b, miR-151b, and miR-301a were separately measured by qPCR. The values are expressed as fold changes (mean $\pm \mathrm{SD}, n=6$ ) when compared with the respective values in control siRNA-transfected cells. ${ }^{*} P<0.05$. (B) ESCC cells were treated as described in Figure 4A, and the expression levels of pri-miR-21, pri-miR-130b, and pri-miR-301a were measured by qPCR of control or KHSRP-specific siRNAs. The values are expressed as fold changes (mean $\pm \mathrm{SD}, n=6$ ) when compared with the respective values in control siRNA-transfected cells. ${ }^{*} P<0.05$. (C) ESCC cells were treated as described in Figure 4A, and expression levels of pre-miR-21, pre-miR-130b, and pre-miR-301a were measured by qPCR of control or KHSRP-specific siRNAs. The values are expressed as fold changes (mean $\pm \mathrm{SD}, n=3$ ) when compared with the respective values in control siRNA-transfected cells. ${ }^{*} P<0.05$. (D) KYSE850 cells were treated as described in Figure 4A, and the expression levels of the 12 putative target mRNAs for miR-130b, miR-21, and miR-301a were measured by qPCR. The values are expressed as fold changes (mean $\pm \mathrm{SD}, n=6$ ) when compared with the respective values in control siRNA-transfected cells. ${ }^{*} P<0.05$. (E) KYSE850 cells were treated as described in Figure 4A, and the levels of BMP6, PDCD4, TIMP3, and KHSRP proteins were measured by Western blot analysis. (F) The levels of miR-21, miR-130b, and miR-301a in total RNA prepared from ESCC cells overexpressing exogenous KHSRP were measured by qPCR. The values are expressed as fold changes (mean $\pm \mathrm{SD}, n=6$ ) when compared with the respective values in control cells (mock). ${ }^{*} P<0.05$. (G) The levels of BMP6, PDCD4, TIMP3, endogenous KHSRP, and exogenous HA-tagged KHSRP proteins in lysates prepared from ESCC cells overexpressing exogenous KHSRP were measured by Western blot analysis. 
to predominantly induce cell proliferation in small cell lung cancer cells by promoting maturation of miR-26a and inhibiting the expression of its target, PTEN [11]. In our study, the effect of KHSRP on proliferation was minimal in ESCC cells, albeit significant. These results suggested that the miRNA maturation-mediated pathway may be important for oncogenic functions of KHSRP regardless of its effects on each malignant phenotype.

A

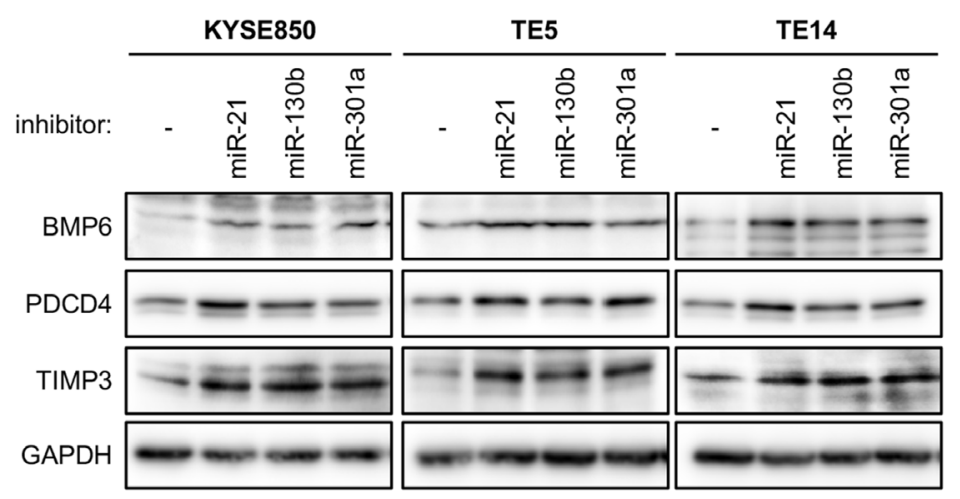

B
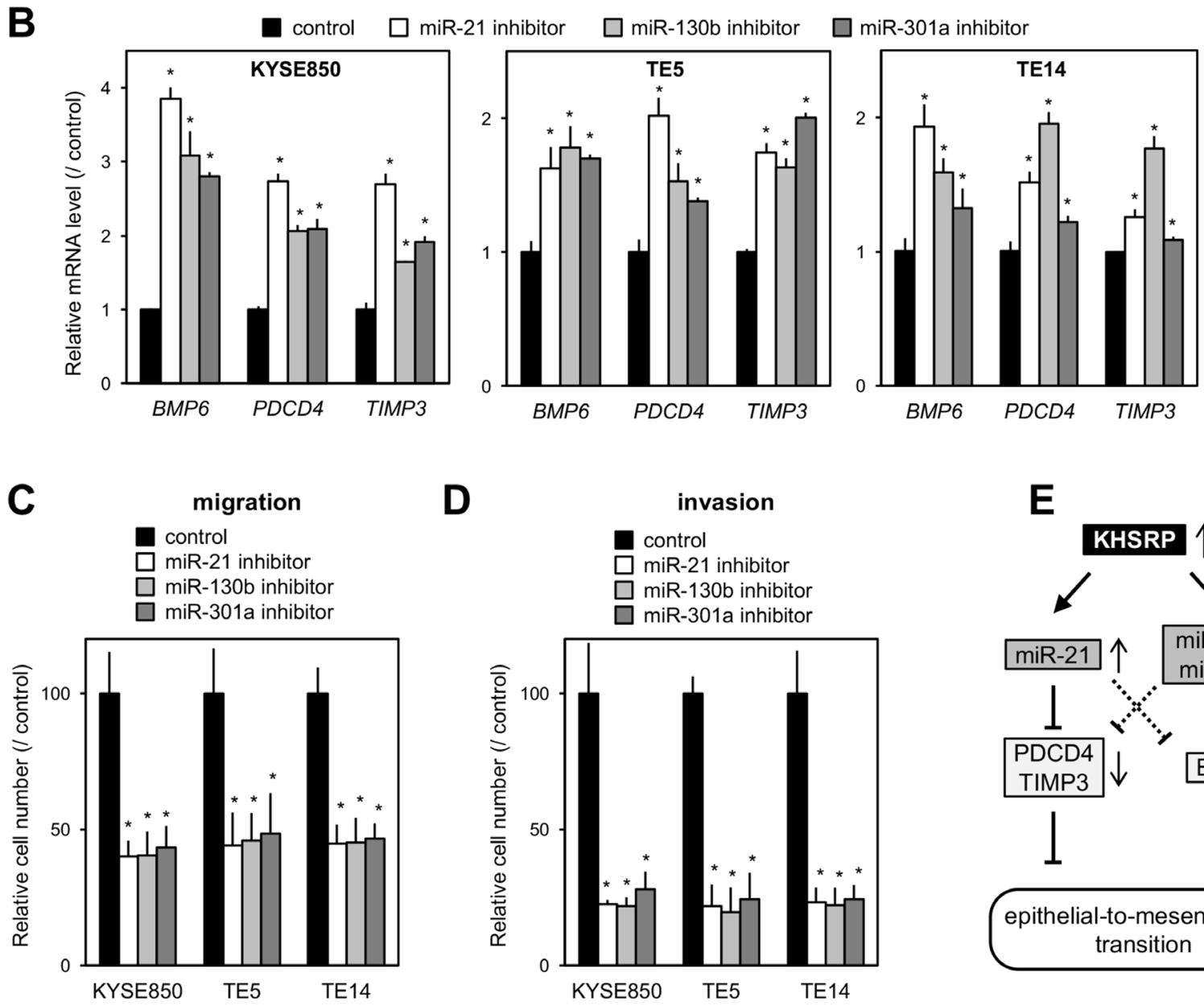

D

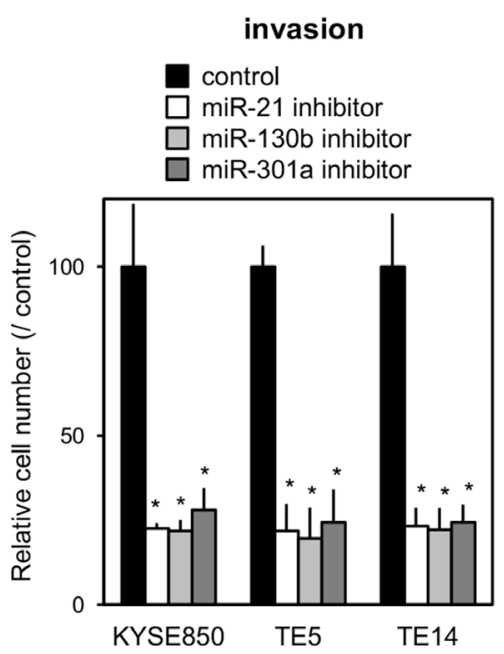

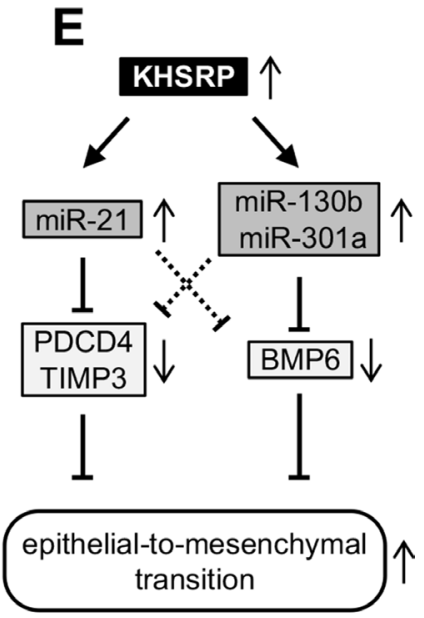

Figure 5: Effects of putative KHSRP target miRNAs on the expression levels of their target mRNAs and ESCC cellular function. (A) ESCC cells were transfected with $30 \mathrm{nM}$ of each of the miRNA-specific inhibitors or control for $48 \mathrm{~h}$. The levels of BMP6, PDCD4, TIMP3, and KHSRP proteins were measured by Western blot analysis. (B) ESCC cells were treated as described in Figure 5A, and the levels of BMP6, PDCD4, and TIMP3 mRNAs were measured by qPCR. The values are expressed as fold changes (mean $\pm \mathrm{SD}$, $n=6$ ) when compared with the respective values in control inhibitor-transfected cells. ${ }^{*} P<0.05$. (C, D) ESCC cells were transfected with $30 \mathrm{nM}$ of each of the miRNA-specific inhibitors or control for $24 \mathrm{~h}$ were added onto BD Falcon Cell Culture Inserts coated without (migration assay; C) or with (invasion assay; D) Matrigel. After incubation for $48 \mathrm{~h}$, cells on the lower surface of filters were determined as described in Figure $2 \mathrm{G}($ mean $\pm \mathrm{SD}, n=3)$. ${ }^{*} P<0.05$. (E) Model depicts the proposed mechanism whereby KHSRP promotes EMT. 
In conclusion, our study suggests that overexpression of KHSRP is involved in the pathogenesis of ESCC by inducing the aggressive phenotype of ESCC cells. KHSRP mainly enhances tumor cell migration and invasion by promoting the maturation of miR-130b, miR-21 and miR-301a and by indirectly inhibiting the expression of their targets, such as endogenous EMT inhibitors BMP6, PDCD4 and TIMP3. Our findings uncover a novel oncogenic function of KHSRP in esophageal tumorigenesis and implicate its use as a marker for prognostic evaluation and as a putative therapeutic target in ESCC. However, molecular mechanisms that underlie upstream and downstream pathways of KHSRPmediated cellular functions in esophageal carcinogenesis remain unclear. In ESCC cell lines, increased expression of the KHSRP protein compared with normal esophagus was more prominently observed than that of the KHSRP mRNA, suggesting that undiscovered mechanisms causing hyperinduction of the KHSRP protein, such as enhanced translation and protein stabilization, contribute to overexpression and activation of oncogenic KHSRP in ESCC. Overexpressed KHSRP could bind to miRNA precursors in both the nucleus and the cytoplasm, but cytoplasmic localization of KHSRP seems to be associated with a more malignant phenotype of tumors in patients with ESCC, suggesting that yet undiscovered mechanisms of cytoplasmic KHSRP may also contribute to its tumorigenic functions. Further studies investigating those mechanisms are necessary, not only to develop interventional methods for targeting KHSRP, but also to explore more appropriate potential biomarkers and therapeutic targets for this disease.

\section{MATERIALS AND METHODS}

\section{Cell lines and primary tissue samples}

A total of 45 ESCC cell lines were used, of which 34 belonged to the KYSE cell line series that were established from surgically resected tumors [41] and obtained from Dr. Yutaka Shimada, or were provided by the Japanese Collection of Research Bioresources (JCRB, Ibaraki, Japan); 10 cell lines were from the TE series provided by the Cell Bank, RIKEN BioResource Center (Tsukuba, Japan), and T.T was provided by JCRB.

ESCC tumor samples were obtained from 104 patients with histologically proven primary ESCC, who underwent esophagectomy (potentially curative R0 resection) without neoadjuvant therapy at Kyoto Prefectural University of Medicine Hospital (Kyoto, Japan) between 1998 and 2011 and at Tokushima University Hospital (Tokushima, Japan) between 2005 and 2011. Samples were embedded in paraffin after $24 \mathrm{~h}$ of formalin fixation. No patients had synchronous or metachronous multiple cancers in other organs. Relevant clinical and survival data were available for all patients.
In this series, all $M_{1}$ tumors had distant lymph node metastases, but no organ metastasis. Disease stage was defined in accordance with the International Union against Cancer tumor-lymph node-metastases classification [42]. The median follow-up period for surviving patients was 40.5 months (ranging from 0.16 to 156.9 months). Formal written consent was obtained from all patients after approval for all aspects of these studies by the local ethics committee (Kyoto Prefectural University of Medicine and Tokushima University).

Total RNA was extracted from frozen tumor tissues and paired non-tumorous tissues using Allprep RNA/ DNA mini kit (Qiagen, Hilden, Germany) according to the manufacturer's protocol.

\section{Antibodies}

Antibodies used in this study are listed in Supplementary Table 4.

\section{Immunohistochemistry and scoring}

Paraffin sections ( $4 \mu \mathrm{m}$ thick) were subjected to IHC staining for each protein by using DAKO EnVision+ Kit/HRP (Agilent Technologies; Santa Clara, CA, USA) for color development with diaminobenzidine tetrahydrochloride as described in a previous report [43].

Tumor tissues were compared with non-tumorous tissues. The percentage of the total cell population expressing the target protein and the overall staining intensity in tumor cells were evaluated in each case at $200 \times$ magnification. The expression of a target protein was considered positive when over $10 \%$ of the tumor cells showed strong or diffuse staining. Nuclear KHSRP staining intensity was considered positive when the cells showed stronger staining compared with the non-tumorous esophageal cells in the parabasal layer, whereas the intensity of cytoplasmic KHSRP staining was considered positive when the cells exhibited some staining. All stained slides were evaluated blindly and independently by two investigators without any knowledge of the clinicopathological data, and any discordant results were resolved by using a conference microscope.

\section{Quantitative real-time PCR for mRNA, pri- miRNA, pre-miRNA, and miRNA}

For quantification of mRNA and pri-miRNA levels, $500 \mathrm{ng}$ of total RNA was reverse-transcribed using ReverTra Ace qPCR RT Master Mix with gDNA Remover kit (TOYOBO, Osaka, Japan). Transcript levels were quantified using specific primer sets (Supplementary Table 5) and SYBR Green Master Mix (Applied Biosystems, Waltham, MA, USA), as described in a previous report [43], or TaqMan kits (Supplementary Table 5) according to the manufacturer's instructions. GAPDH mRNA levels were used as an internal control for normalization. 
For quantification of pre-miRNA levels, $500 \mathrm{ng}$ of total RNA was used as a template to generate the firststrand cDNA for pre-miRNA using miScript II RT kit (Supplementary Table 5; Qiagen). Transcript levels were quantified using miScript Precursor Assay (Qiagen) and miScript SYBR Green PCR Kits (Qiagen) according to the manufacturer's instructions. RNU6 snoRNA levels were similarly measured and used as an internal control for normalization.

For quantification of miRNA levels, $10 \mathrm{ng}$ of total RNA was used as a template to generate specific firststrand cDNA for miRNAs using a TaqMan-specific miRNA reverse transcription kit (Supplementary Table 5; Applied Biosystems). RNU44 snoRNA levels were similarly measured and used as an internal control for normalization.

\section{Western blot analysis}

Whole-cell lysate preparation and Western blot analysis using GAPDH as a loading control were performed as previously described [43]. Images were obtained with a GE Amersham Imager 600 (GE Healthcare, Milwaukee, WI, USA), and band intensities were quantified using ImageQuant TL 8.1 software (GE Healthcare).

Subcellular components were isolated using a LysoPure Nuclear and Cytoplasmic Extractor kit (Wako Pure Chemical Industries, Osaka, Japan) according to the manufacturer's instructions.

\section{Fluorescent immunocytochemistry (FIC)}

Cells were cultured on chamber slides, fixed in 4\% paraformaldehyde for $10 \mathrm{~min}$ at room temperature and permeabilized with $0.1 \%$ Triton X-100 in phosphatebuffered saline for $10 \mathrm{~min}$ at room temperature. FIC was performed as described previously [43]. After mounting using ProLong Gold Antifade Reagent with 4',6-diamidino-2-phenylindole (DAPI), cells were observed under a fluorescence microscope (LSM510; Carl Zeiss, Oberkochen, Germany).

\section{Plasmid construction}

The N-terminal HA-tagged full coding sequence of human KHSRP (NM_022037) was amplified by PCR (Supplementary Table 5) using Halo-tagged KHSRP expression plasmid, pFN21AE2201, obtained from Kazusa DNA Research Institute (Chiba, Japan), and cloned into the retroviral vector pMXs-Neo (Cell Biolabs, San Diego, CA, USA).

\section{Transient transfection experiments}

siRNAs targeting mRNA of KHSRP (\#1-3), or control siRNAs (Supplementary Table 6) were transfected into cells at a final concentration of $10 \mathrm{nM}$. The inhibitor for each miRNA or a negative control (Supplementary Table 6) was transfected at a final concentration of $30 \mathrm{nM}$ using Lipofectamine RNAiMax reagent (Invitrogen, Carlsbad, CA, USA) according to the manufacturer's instructions.

\section{Stable transfection experiments}

To establish ESCC cell lines stably overexpressing KHSRP, cells were infected with HA-tagged KHSRPexpressing retroviruses and selected by treatment with 0.5 $\mathrm{mg} / \mathrm{mL}$ of G418 for 4 weeks. Control cells were obtained using retroviruses obtained from the empty pMXsNeo vector that was packaged in PLAT-A cells. Crude transfectants were subcultured and tested for exogenous KHSRP overexpression using an anti-HA antibody.

\section{Cell proliferation}

Cell growth was assessed at the indicated times after seeding $\left(2 \times 10^{4}\right.$ cells/24-well plate $)$ using a watersoluble tetrazolium (WST) salt assay (Cell Counting Kit-8; Dojindo, Mashikimachi, Japan) according to the manufacturer's instructions. The results are expressed as the mean absolute absorbance at the indicated time divided by the mean absolute absorbance of each sample cultured for $24 \mathrm{~h}$ after seeding.

Spheroid formation was performed as described previously [44]. Briefly, $100 \mu \mathrm{L} /$ well of cell suspensions $(1000$ cells $/ \mathrm{mL})$ were dispensed into PrimeSurface 96-well round-bottomed plates (Sumitomo Bakelite, Tokyo, Japan). Plates were centrifuged for $5 \mathrm{~min}$ at $200 \times \mathrm{g}$ and incubated at $37^{\circ} \mathrm{C}$ in an atmosphere of $5 \% \mathrm{CO}_{2}$. The areas of formed spheroids were determined using ImageJ software (http://imagej.nih.gov/ij/).

\section{Scratch-wound healing assay}

The transfectants were dispensed into the ibidi Culture-Inserts (ibidi GmbH, Munich, Germany). After $24 \mathrm{~h}$, the Culture-Inserts were removed, and the area of the wound was observed under a microscope. The remaining scratch areas were analyzed with ImageJ software. The migration rate was determined as a percentage reduction of the initial scratch area.

\section{Transwell migration and invasion assays}

Transwell migration and invasion assays were carried out in 24-well modified Boyden chambers (BD transduction, Franklin Lakes, NJ). The upper surface of the $6.4 \mathrm{~mm}$ diameter filters with $8 \mu \mathrm{m}$ pores was precoated with (invasion assay) or without (migration assay) Matrigel (BD transduction). Transfectants $\left(5 \times 10^{4}\right.$ cells/ well) were transferred into the upper chamber. Following 
$48 \mathrm{~h}$ of incubation, migrated or invasive cells on the lower surface of filters were fixed and stained with Diff-Quik stain (Sysmex, Kobe, Japan). Stained cell nuclei were counted in triplicates. We assessed the migration and invasive potential of each transfectant by calculating the ratio of the percentages to their control counterparts.

\section{Microarray analysis}

Total RNA for gene expression analysis was isolated using RNA-Iso Plus reagent (Takara, Shiga, Japan), whereas total RNA for miRNA expression analysis was isolated using NucleoSpin miRNA kit (Takara). Microarray data for mRNAs and miRNAs were obtained using a whole human genome microarray or a human miRNA microarray $(8 \times 60 \mathrm{k}$, Agilent Technologies $)$, respectively, as described previously [43, 45], and analyzed using GeneSpring 13.0 software (Agilent Technologies). All microarray data are available at the Gene Expression Omnibus (GSE99422, GSE99423).

Predicted targets for these differentially expressed miRNAs were identified using TarBase v7.0 (http://www. microrna.gr/tarbase) to provide experimentally validated target genes for miRNAs [46].

Enrichment analyses of the set of the predicted target genes for differentially expressed miRNAs and functional pathways related to this gene set were performed using KEGG pathway analysis. Over-representation of specific KEGG pathways in a gene set was statistically analyzed by DAVID Bioinformatics Resources 6.7 software (http:// david.abcc.ncifcrf.gov/home.jsp) [47, 48]. The nominal $P$-value and the Benjamini-Hochberg false discovery rate (adjusted $P$-value) were used to determine the significance of enrichment or over-representation of terms for each annotation.

\section{Ribonucleoprotein immunoprecipitation (RIP)}

Immunoprecipitation of ribonucleoprotein complexes was performed using a RiboCluster Profiler RIP-Assay kit (Medical \& Biological Laboratories, Nagoya, Japan) according to the manufacturer's protocol. Briefly, HEK293 cells transiently expressing Halotagged KHSRP (KHSRP-Halo) were crosslinked on ice by irradiation with UV light $(365 \mathrm{~nm})$ at $150 \mathrm{~mJ} / \mathrm{cm}^{2}$. Cytoplasmic lysates $(250 \mu \mathrm{g}$ protein) or nuclear extracts (250 $\mu \mathrm{g}$ protein) were incubated for $3 \mathrm{~h}$ at $4^{\circ} \mathrm{C}$ with $50 \mu \mathrm{L}$ of a $50 \%(\mathrm{v} / \mathrm{v})$ suspension of HaloLink Resin (Promega, Madison, WI, USA). After the resin was treated with HaloTEV protease (Promega), the IP immunoprecipitated transcripts were quantified by qPCR.

\section{Statistical analysis}

The clinicopathological variables pertaining to the corresponding patients were analyzed by $\chi^{2}$ or Fisher's exact test. For survival analysis, Kaplan-Meier survival curves were constructed for groups based on univariate predictors, and differences among the groups were tested with the log-rank test. Univariate and multivariate survival analyses were performed using the likelihood ratio test of the stratified Cox proportional hazards model. Differences among subgroups were tested with Student's $t$-test or with analysis of variance and Tukey's multiple comparison test. Differences were assessed with a two-sided test and considered significant at $P<0.05$.

\section{Author contributions}

Y.F., K.M., J.H., K.S., and I.I. contributed to the conception and design of the study. Y.F., K.M., J.H., K.S., S.H., Y.M., M.W., and R.T. performed the experimental work. T.N., S.T., and T.K. analyzed microarray data. I.I., K.M., and M.S. interpreted and analyzed results. Y.K., H.F, D.I., A.T., and E.O. provided human material and scored IHC staining. All the co-authors were involved in writing the manuscript. I.I. conceptualized and supervised the whole project study as a senior author. All the authors have reviewed the manuscript.

\section{ACKNOWLEDGMENTS}

We thank Hideaki Horikawa (Support Center for Advanced Medical Sciences, Graduate School of Biomedical Sciences, Tokushima University, Tokushima, Japan) and Yuki Kuwano (Department of Pathophysiology, Graduate School of Biomedical Sciences, Tokushima University, Tokushima, Japan) for their technical assistances.

\section{CONFLICTS OF INTEREST}

The authors declare no conflicts of interest.

\section{FUNDING}

This study was supported in part by Japan Society for the Promotion of Science (16K15618, 15K08949) and by Japan Agency for Medical Research and development (16km0506001h004).

\section{REFERENCES}

1. Okines A, Cunningham D, Chau I. Targeting the human EGFR family in esophagogastric cancer. Nat Rev Clin Oncol. 2011; 8:492-503.

2. Enzinger PC, Mayer RJ. Esophageal cancer. N Engl J Med. 2003; 349:2241-2252.

3. Briata P, Bordo D, Puppo M, Gorlero F, Rossi M, PerroneBizzozero N, Gherzi R. Diverse roles of the nucleic acid- 
binding protein KHSRP in cell differentiation and disease. Wiley Interdiscip Rev RNA. 2016; 7:227-240.

4. Briata P, Chen CY, Ramos A, Gherzi R. Functional and molecular insights into KSRP function in mRNA decay. Biochim Biophys Acta. 2013; 1829:689-694.

5. Gherzi R, Chen CY, Trabucchi M, Ramos A, Briata P. The role of KSRP in mRNA decay and microRNA precursor maturation. Wiley Interdiscip Rev RNA. 2010; 1:230-239.

6. Harada K, Baba Y, Ishimoto T, Shigaki H, Kosumi K, Yoshida N, Watanabe M, Baba $\mathrm{H}$. The role of microRNA in esophageal squamous cell carcinoma. J Gastroenterol. 2016; 51:520-530.

7. Malz M, Weber A, Singer S, Riehmer V, Bissinger M, Riener MO, Longerich T, Soll C, Vogel A, Angel P, Schirmacher P, Breuhahn K. Overexpression of far upstream element binding proteins: a mechanism regulating proliferation and migration in liver cancer cells. Hepatology. 2009; 50:1130-1139.

8. Bikkavilli RK, Malbon CC. Dishevelled-KSRP complex regulates Wnt signaling through post-transcriptional stabilization of beta-catenin mRNA. J Cell Sci. 2010; 123:1352-1362.

9. Yang J, Fan J, Li Y, Li F, Chen P, Fan Y, Xia X, Wong ST. Genome-wide RNAi screening identifies genes inhibiting the migration of glioblastoma cells. PLoS One. 2013; 8:e61915.

10. Puppo M, Bucci G, Rossi M, Giovarelli M, Bordo D, Moshiri A, Gorlero F, Gherzi R, Briata P. miRNA-Mediated KHSRP silencing rewires distinct post-transcriptional programs during TGF-beta-induced epithelial-tomesenchymal transition. Cell Rep. 2016; 16:967-978.

11. Tong L, Luo Y, Wei T, Guo L, Wang H, Zhu W, Zhang J. KH-type splicing regulatory protein (KHSRP) contributes to tumorigenesis by promoting miR-26a maturation in small cell lung cancer. Mol Cell Biochem. 2016; 422:61-74.

12. Trabucchi M, Briata P, Garcia-Mayoral M, Haase AD, Filipowicz W, Ramos A, Gherzi R, Rosenfeld MG. The RNA-binding protein KSRP promotes the biogenesis of a subset of microRNAs. Nature. 2009; 459:1010-1014.

13. Bronnum H, Andersen DC, Schneider M, Sandberg MB, Eskildsen T, Nielsen SB, Kalluri R, Sheikh SP. miR-21 promotes fibrogenic epithelial-to-mesenchymal transition of epicardial mesothelial cells involving Programmed Cell Death 4 and Sprouty-1. PLoS One. 2013; 8:e56280.

14. Dong P, Karaayvaz M, Jia N, Kaneuchi M, Hamada J, Watari H, Sudo S, Ju J, Sakuragi N. Mutant p53 gain-offunction induces epithelial-mesenchymal transition through modulation of the miR-130b-ZEB1 axis. Oncogene. 2013; 32:3286-3295.

15. Lu Y, Gao W, Zhang C, Wen S, Huangfu H, Kang J, Wang B. Hsa-miR-301a-3p acts as an oncogene in laryngeal squamous cell carcinoma via target regulation of Smad4. J Cancer. 2015; 6:1260-1275.
16. Liu G, Liu YJ, Lian WJ, Zhao ZW, Yi T, Zhou HY. Reduced BMP6 expression by DNA methylation contributes to EMT and drug resistance in breast cancer cells. Oncol Rep. 2014; 32:581-588.

17. Coppola V, Musumeci M, Patrizii M, Cannistraci A, Addario A, Maugeri-Sacca M, Biffoni M, Francescangeli F, Cordenonsi M, Piccolo S, Memeo L, Pagliuca A, Muto G, et al. BTG2 loss and miR-21 upregulation contribute to prostate cell transformation by inducing luminal markers expression and epithelial-mesenchymal transition. Oncogene. 2013; 32:1843-1853.

18. Xu H, Wang $\mathrm{X}$, Liu M, He X. Tangzhiqing granules alleviate podocyte epithelial-mesenchymal transition in kidney of diabetic rats. Evid Based Complement Alternat Med. 2017. 2017:1479136.

19. de Marcondes PG, Morgado-Diaz JA. The role of EphA4 signaling in radiation-induced EMT-like phenotype in colorectal cancer cells. J cell biochem. 2017; 118:442-445.

20. Chandramouli A, Simundza J, Pinderhughes A, Cowin P. Choreographing metastasis to the tune of LTBP. J Mammary Gland Biol Neoplasia. 2011; 16:67-80.

21. Hu W, Jin P, Ding C, Liu W. miR-19a/b modulates lung cancer cells metastasis through suppression of MXD1 expression. Oncol Lett. 2016; 12:1901-1905.

22. Malouf GG, Taube JH, Lu Y, Roysarkar T, Panjarian S, Estecio MR, Jelinek J, Yamazaki J, Raynal NJ, Long H, Tahara T, Tinnirello A, Ramachandran P, et al. Architecture of epigenetic reprogramming following Twist1-mediated epithelial-mesenchymal transition. Genome Biol. 2013; 14:R144.

23. Bujko M, Kober P, Mikula M, Ligaj M, Ostrowski J, Siedlecki JA. Expression changes of cell-cell adhesionrelated genes in colorectal tumors. Oncol Lett. 2015; 9:2463-2470.

24. Gan X, Wang C, Patel M, Kreutz B, Zhou M, Kozasa T, Wu D. Different Raf protein kinases mediate different signaling pathways to stimulate E3 ligase RFFL gene expression in cell migration regulation. J Biol Chem. 2013; 288: 33978-33984.

25. Woods A, Couchman JR. Syndecans: synergistic activators of cell adhesion. Trends Cell Biol. 1998; 8:189-192.

26. Martin del Campo SE, Latchana N, Levine KM, Grignol VP, Fairchild ET, Jaime-Ramirez AC, Dao TV, Karpa VI, Carson M, Ganju A, Chan AN, Carson WE 3rd. MiR-21 enhances melanoma invasiveness via inhibition of tissue inhibitor of metalloproteinases 3 expression: in vivo effects of MiR-21 inhibitor. PLoS One. 2015; 10:e115919.

27. Luo F, Ji J, Liu Y, Xu Y, Zheng G, Jing J, Wang B, Xu W, Shi L, Lu X, Liu Q. MicroRNA-21, up-regulated by arsenite, directs the epithelial-mesenchymal transition and enhances the invasive potential of transformed human bronchial epithelial cells by targeting PDCD4. Toxicol lett. 2015; 232:301-309. 
28. Ferraro A, Kontos CK, Boni T, Bantounas I, Siakouli D, Kosmidou V, Vlassi M, Spyridakis Y, Tsipras I, Zografos G, Pintzas A. Epigenetic regulation of miR-21 in colorectal cancer: ITGB4 as a novel miR-21 target and a three-gene network (miR-21-ITGBeta4-PDCD4) as predictor of metastatic tumor potential. Epigenetics. 2014; 9:129-141.

29. Wang N, Zhang CQ, He JH, Duan XF, Wang YY, Ji X, Zang WQ, Li M, Ma YY, Wang T, Zhao GQ. MiR-21 downregulation suppresses cell growth, invasion and induces cell apoptosis by targeting FASL, TIMP3, and RECK genes in esophageal carcinoma. Dig Dis Sci. 2013; 58:1863-1870.

30. Zubaidah RM, Tan GS, Tan SB, Lim SG, Lin Q, Chung MC. 2-D DIGE profiling of hepatocellular carcinoma tissues identified isoforms of far upstream binding protein (FUBP) as novel candidates in liver carcinogenesis. Proteomics. 2008; 8:5086-5096.

31. Pruksakorn D, Teeyakasem P, Klangjorhor J, Chaiyawat P, Settakorn J, Diskul-Na-Ayudthaya P, Chokchaichamnankit D, Pothacharoen P, Srisomsap C. Overexpression of $\mathrm{KH}$-type splicing regulatory protein regulates proliferation, migration, and implantation ability of osteosarcoma. Int J Oncol. 2016; 49:903-912.

32. Boucas J, Fritz C, Schmitt A, Riabinska A, Thelen L, Peifer M, Leeser U, Nuernberg P, Altmueller J, Gaestel M, Dieterich C, Reinhardt HC. Label-free protein-RNA interactome analysis identifies Khsrp signaling downstream of the p38/Mk2 kinase complex as a critical modulator of cell cycle progression. PLoS One. 2015; 10:e125745.

33. Bauer WJ, Heath J, Jenkins JL, Kielkopf CL. Three RNA recognition motifs participate in RNA recognition and structural organization by the pro-apoptotic factor TIA-1. J Mol Biol. 2012; 415:727-740.

34. Kullmann M, Gopfert U, Siewe B, Hengst L. ELAV/Hu proteins inhibit p27 translation via an IRES element in the p27 5'UTR. Genes Dev. 2002; 16:3087-3099.

35. Mazan-Mamczarz K, Galban S, Lopez de Silanes I, Martindale JL, Atasoy U, Keene JD, Gorospe M. RNAbinding protein $\mathrm{HuR}$ enhances p53 translation in response to ultraviolet light irradiation. Proc Natl Acad Sci USA. 2003; 100:8354-8359.

36. $\mathrm{Xu} \mathrm{N}$, Chen $\mathrm{CY}$, Shyu AB. Versatile role for hnRNP D isoforms in the differential regulation of cytoplasmic mRNA turnover. Mol Cell Biol. 2001; 21:6960-6971.

37. Dai F, Mei L, Meng S, Ma Z, Guo W, Zhou J, Zhang J. The global expression profiling in esophageal squamous cell carcinoma. Genomics. 2017; 109:241-250. https://doi. org/10.1016/j.ygeno.2017.04.005.

38. Kishore S, Jaskiewicz L, Burger L, Hausser J, Khorshid M, Zavolan M. A quantitative analysis of CLIP methods for identifying binding sites of RNA-binding proteins. Nat methods. 2011; 8:559-564.
39. Moshiri A, Puppo M, Rossi M, Gherzi R, Briata P. Resveratrol limits epithelial to mesenchymal transition through modulation of KHSRP/hnRNPA1-dependent alternative splicing in mammary gland cells. Biochim Biophys Acta. 2017; 1860:291-298.

40. Rodriguez Calleja L, Jacques C, Lamoureux F, Baud'huin M, Tellez Gabriel M, Quillard T, Sahay D, Perrot P, Amiaud J, Charrier C, Brion R, Lecanda F, Verrecchia F, et al. $\Delta \mathrm{Np} 63 \alpha$ silences a miRNA program to aberrantly initiate a woundhealing program that promotes TGF $\beta$-induced metastasis. Cancer Res. 2016; 76:3236.

41. Shimada Y, Imamura M, Wagata T, Yamaguchi N, Tobe T. Characterization of 21 newly established esophageal cancer cell lines. Cancer. 1992; 69:277-284.

42. Sobin LH, Gospodarowicz MK, Wittekind C, International Union against Cancer. TNM classification of malignant tumours. (Chichester, West Sussex, UK ; Hoboken, NJ: Wiley-Blackwell). 2010.

43. Hamada J, Shoda K, Masuda K, Fujita Y, Naruto T, Kohmoto T, Miyakami Y, Watanabe M, Kudo Y, Fujiwara H, Ichikawa D, Otsuji E, Imoto I. Tumor-promoting function and prognostic significance of the RNA-binding protein T-cell intracellular antigen-1 in esophageal squamous cell carcinoma. Oncotarget. 2016; 7:17111-17128. https://doi. org/10.18632/oncotarget.7937.

44. Kajiura K, Masuda K, Naruto T, Kohmoto T, Watabnabe M, Tsuboi M, Takizawa H, Kondo K, Tangoku A, Imoto I. Frequent silencing of the candidate tumor suppressor TRIM58 by promoter methylation in early-stage lung adenocarcinoma. Oncotarget. 2017; 8:2890-2905. https:// doi.org/10.18632/oncotarget.13761.

45. Kurokawa K, Tanahashi T, Iima T, Yamamoto Y, Akaike Y, Nishida K, Masuda K, Kuwano Y, Murakami Y, Fukushima M, Rokutan K. Role of miR-19b and its target mRNAs in 5-fluorouracil resistance in colon cancer cells. J Gastroenterol. 2012; 47:883-895.

46. Vlachos IS, Paraskevopoulou MD, Karagkouni D, Georgakilas G, Vergoulis T, Kanellos I, Anastasopoulos IL, Maniou S, Karathanou K, Kalfakakou D, Fevgas A, Dalamagas T, Hatzigeorgiou AG. DIANA-TarBase v7.0: indexing more than half a million experimentally supported miRNA:mRNA interactions. Nucleic Acids Res. 2015; 43:D153-159.

47. Huang da W, Sherman BT, Lempicki RA. Systematic and integrative analysis of large gene lists using DAVID bioinformatics resources. Nat Protoc. 2009; 4:44-57.

48. Huang da W, Sherman BT, Lempicki RA. Bioinformatics enrichment tools: paths toward the comprehensive functional analysis of large gene lists. Nucleic Acids Res. 2009; 37:1-13. 